\title{
Pregnancy Risk Perception and Associated Factors Among Pregnant Women Attending Antenatal Care at Health Centers in Jabitehnan District, Amhara, Northwest Ethiopia
}

\section{Demeke Andebet Alemu}

Debre Markos University

Ambaye Minayehu Minayehu Zegeye ( $\square$ abelminayehu15@gmail.com )

Assosa University

Wale Kumlachew Dessie

Assosa University

Liknaw Bewket Zeleke

Debre Markos University

Dawit Misganaw Belay

Assosa University

\section{Research}

Keywords: Associated factors, Jabitenhan district, Pregnancy, Risk perception

Posted Date: November 22nd, 2021

DOI: https://doi.org/10.21203/rs.3.rs-1041971/v1

License: (c) (i) This work is licensed under a Creative Commons Attribution 4.0 International License.

Read Full License 


\section{Abstract}

Background: Pregnancy risk perception affects a pregnant woman's decision about health care services use such as prenatal care, place of birth, choices about medical interventions, adherence to medical procedures, and recommendations.

Methods: An institutional-based cross-sectional study was conducted among 424 mothers attending ANC at health centers in the Jabitenhan district from April 1 to 30, 2021. Data was collected through a face-toface interview using a structured questionnaire which was developed according to the health belief model. The logistic regression model was used using adjusted odds ratio with $95 \% \mathrm{Cl}$ and $\mathrm{p}$ value $<0.05$

Result: 424 pregnant women were interviewed of which nearly half of the respondents (48\%) had good pregnancy risk perception. Women who had a history of obstetric complication (AOR:95\% Cl = 3.44:1.73,6.83), those who know at least one pregnancy danger sign (AOR:95\% Cl $=5.22 ; 2.46,11.07)$, pregnant women who had a bad obstetric history $(A O R: 95 \% \mathrm{Cl}=2.23: 1.13,4.41)$ and knowing women who died due to pregnancy-related complications (AOR:95\% Cl $=2.85: 1.45,5.60)$ were more likely to have good perception towards pregnancy risk as compared to their counterparts.

Conclusion: Obstetric complications, awareness of pregnancy danger signs, bad obstetric history, and knowing women who died due to pregnancy-related complications were found to be significantly associated with pregnancy risk perception.

\section{Plain English Summary}

Pregnancy risk perception affects a pregnant woman's decision about health care services use such as prenatal care, place of birth, choices about medical interventions, adherence to medical procedures, and recommendations. 424 pregnant women were interviewed and nearly half of the respondents $(48 \%)$ had good pregnancy risk perception. The major factors identified on pregnancy risk perception were women who had a history of obstetric complication, who know at least one pregnancy danger sign, who had a bad obstetric history and knowing women who died due to pregnancy-related complications.

In conclusion, pregnant women perceive that they were risky in developing pregnancy-related complications and their consequences were low. For health care provider's routine screening of pregnant women's pregnancy risk perception especially women's before they experience obstetric complications and bad obstetric outcomes should be conducted and design effective education and counseling about their susceptibility to pregnancy risk and the consequences of pregnancy-related complications.

\section{Introduction}

Risk is the probability that a person will be harmed (1). Risk perception means an individual's expectation about the probability, characteristics, and severity of an event. It is an important construct for different health behavior theories such as Health Belief Model, Protection Motivation Theory, and Prospect 
Theory(2). An individual making judgment about the probability of an event is based on past experience(3)

A greater perception of health risk leads to conduct protective action. Therefore understanding people's health risk perception and the accuracy of their perception is important(4). Pregnancy risk perception affects a pregnant woman's decision about health care services use like prenatal care, place of birth, choices about medical interventions, adherence to medical procedures and recommendations, and health behaviors (5-7).

Pregnancy is a normal physiologic process but some of the common discomforts of pregnancy may make the pregnant woman feels ill. Ranging from mildly irritating to life-threatening conditions(8). Pregnancy and childbirth are often perceived as normal life events without justification in many developing countries including Ethiopia. Obstetric complications are high among normal pregnancies. These complications occurred following warning signs called obstetric danger signs (9-12).

The top commonly manifested danger signs during labour and childbirth are severe vaginal bleeding, prolonged labour, convulsion, and retained placenta. Besides, dangerous signs occur during the postnatal period which includes severe vaginal bleeding, unconsciousness, and fever $(13,14)$. Every pregnant woman is at risk of facing pregnancy-related complications that could end in death or injury to both herself or her newborn(15). From pregnancy-related complications, hemorrhage, obstructed labour, pregnancy-induced hypertension, puerperal sepsis, and unsafe abortion are the five leading causes of maternal death in Ethiopia from 1990 to 2016. Early detection and management of those complications are important to reduce maternal mortality(16).

Pregnancy and childbirth complications are major causes of maternal death. Complications develop during pregnancy accounted $72.5 \%$ of maternal death are called direct causes of maternal death. Globally the magnitudes of direct cause's maternal death are hemorrhage (27.1\%), pregnancy-induced hypertension (14\%), puerperal sepsis (10.7\%), and unsafe abortion (7.9\%). In Ethiopia, hemorrhage (29.9\%), obstructed labor (22.34\%), pregnancy-induced hypertension (16.9\%), puerperal sepsis (14.68\%), and unsafe abortion $(8.6 \%)$ are major causes of maternal death $(16,17,18)$

Due to obstetric complications globally every day 810 women died. The developing country accounted for $94 \%(277,300)$ of these deaths. Of these eighty-six percent of deaths are occurred in both Sub-Saharan Africa and Southern. Sub-Saharan Africa has the highest MMR at $66.44 \%$ (196 000) of maternal deaths annually. In Ethiopia, the maternal mortality ratio is significantly reduced from 1030 death per 100,000 live births(2000) to 401 death per 100,000 live births(2017) but it remains high(19).

The maternal mortality ratio in developing countries in 2015 is twenty times higher than in developed countries. The difference in maternal mortality ratio is also present within countries between urban and rural residents, and between high and low-income women (20). 
Pregnancy and childbirth-related mortality are unavoidable due to three delays. These are delays in deciding to seek care, delays in accessing and reaching appropriate care, and delay in the recipient of appropriate care once a health facility is reached. The first delay influences the probability of the second and third delay. Their poor perception of pregnancy-related risks and complications leads pregnant women to delay decision-making to seek obstetric care $(21,22)$

Therefore, this study is intended to determine pregnancy risk perception and associated factors among pregnant women attending antenatal care at health centers in Jabitehnan district, Amhara, northwest Ethiopia, 2021

\section{Material And Methods}

\subsection{Study Area and Period.}

The study was conducted in Jabitehnan District, West Gojjam zone, Amhara region, northwest Ethiopia. Jabitenhnan is bordered on the southwest by Dembech, on the west by Bure, on the northwest by Sekela, on the north by Kuarit, and on the east of Degadamot districts. It is located $387 \mathrm{~km}$ from Addis Ababa in the northwest part of Ethiopia. According to the report from the district in 2016, it has 39 kebeles with a total population of 218,447 and 125,323 adults. In the district, there are 11 health centers and 39 health posts. The health centers give different clinical services such as family planning, antenatal care, delivery, testing of HIV, etc. for the nearby community. All health centers provide ANC service for the nearby community The majority of the inhabitants practiced Orthodox Christianity $(97.96 \%)$ while $2.02 \%$ were Muslim $(23,24)$. This study was conducted from April 01, 2021, to April 30, 2021

\subsection{Study Design.}

The institutional-based cross-sectional study design was conducted.

\subsection{Source and Study Population.}

Source population of this study was all pregnant women coming to antenatal care service in Jabitehnan district health centers and the study population was all pregnant women attending to antenatal care service in Jabitehnan district health centers during the data collection period

\subsection{Sample Size Determination.}

The sample size was calculated using the single population proportions formula by considering $50 \%$ of the population has good pregnancy risk perception. The size of the sample was calculated as follows: 


$$
\mathrm{n}=\frac{\mathrm{Z}^{2} \alpha / 2 \times(\mathrm{p}(1-\mathrm{p}))}{\mathrm{d}^{2}}
$$

$\mathbf{n}$ - Was the sample size.

$\mathbf{Z}^{2} \boldsymbol{\alpha} / \mathbf{2}$ - Was the $95 \%$ confidence interval (standard value of 1.96 )

$\mathbf{P}$ - Was the estimated proportion of patients with good pregnancy risk perception $=50 \%$

d - Was the margin of error (precision error) $= \pm 5 \%$

$\mathrm{n}=\frac{(1.96) 2 \times 0.5 \times 0.5}{(0.05) 2}=385$

Then by adding a $10 \%$ non-response rate, the total sample size was 424

\subsection{Sampling Technique and Procedure.}

There are eleven health centers in the Jabitehnan district. All health centers were included in the study and a systematic sampling technique was used to collect data. The total number of pregnant women attending ANC per month for the previous three consecutive months in each health center was taken from the ANC tally record book. The average number of pregnant women attending ANC per month was calculated. Based on the total number of pregnant women attending antenatal care in Jabitehnan district health center the total sample was divided to each health center proportionally. $P=n / N$ then $P$ times by total antenatal care attendant per month in each health center (Fig 1).

\subsection{Inclusion and Exclusion Criteria}

\subsubsection{Inclusion Criteria.}

Pregnant women coming to antenatal care service in Jabitehnan district health centers

\subsubsection{Exclusion Criteria.}

Women who were critically ill during the data collection period

\subsection{Study Variables.}




\subsubsection{Dependent Variables}

Pregnancy risk perception (poor/good)

\subsubsection{Independent Variables}

$\sqrt{ }$ Socio-demographic factors (age, marital status, education, occupation, religion, place of residence, income, partner education)

$\sqrt{ }$ Knowing a woman who died due to pregnancy-related complications

$\sqrt{ }$ Obstetric factors (gravidity, parity, history of obstetric complications, having pregnancy danger signs, number of ANC visit, bad obstetric history)

$\sqrt{ }$ Knowledge of pregnancy danger signs

\subsection{Data Collection Tools.}

The tool has four parts. These are socio-demographic characteristics, obstetric characteristics, Knowledge of pregnancy danger signs, and pregnancy risk perception using the two constructs of health belief model. These tools were first prepared in English and later translated into Amharic (local language) and back to English again to maintain its consistency. The socio-demographic variables, obstetric characteristics, and knowledge of pregnancy danger sign was assessed as a factor for pregnancy risk perception using two constructs of health belief model.

The client's knowledge of pregnancy danger signs was assessed as a factor for their perception of pregnancy risk. Knowledge about pregnancy danger signs (yes or no options for being familiar with each pregnancy danger sign). This tool consists of 11 questions, which focus on general knowledge of pregnancy danger signs.

The client's pregnancy risk perception using health belief model constructs was assessed. Clients are asked question of two constructs of health belief model that ranges from five to twenty-five score for perceived susceptibility and seven to thirty-five score for perceived severity. The total scores were calculated from the combined questions ranges from twelve to sixty. The questions has five options ( $1=$ strongly disagree,2=disagree, $3=$ neutral, $4=$ =agree, $5=$ strongly agree)(25).

\subsection{Data Collection Procedure.}

Eleven trained midwives collected the data through a face-to-face interview. The data collectors and supervisors had taken training on the objective of the study, methods of data collection procedures, and tool of data collection for one day by the researcher 


\subsection{Data Quality Control.}

To ensure the data quality training was given to data collectors and supervisors by the principal investigator on how to conduct client interviews. A pre-test was conducted in $5 \%$ of the sample on March 2021 Finote Selam health center. Cronbach's alphas ( 0.89 up to 0.90$)$ were calculated to check the internal consistency and reliability of the item. The necessary modification was made for any ambiguity, confusion, and difficult words based on pre-test data analysis. Each data collector and supervisor checked before and immediately after collection for the completeness and consistency of the questionnaire.

\subsection{Data processing and Analysis.}

The data was cleaned, coded and entered, and analyzed using Statistical Package for social sciences (SPSS) version 20. Descriptive statistics such as frequency, percentage, standard deviation, and mean were used to characterize the participants in terms of socio-demographic variables, obstetric variables, and knowledge of pregnancy danger signs. A logistic regression model was fitted to assess the association between dependent and independent variables with a P-value of 0.25 or less in the bivariable analysis will be included in the multivariable analysis. The adjusted odds ratio together with $95 \%$ confidence intervals was computed and, results with P-value $<0.05$ were considered to declare a result as significantly associated.

\section{Results}

\subsection{Socio-demographic characteristics.}

Four hundred twenty-one pregnant women have completed the questionnaire making the response rate of the study $99.3 \%$. The mean age of respondents was $26.99 \pm 6.22$ and nearly one-third $33.3 \%$ of respondents were age between 25 and 29 years. All respondents were Amhara in ethnicity and 93.8\% were orthodox in religion. All most all the respondents $99.8 \%$ were married and more than half $58.7 \%$ of the respondents were housewives. Of the total study participants, $57 \%$ respondents were living in rural. Concerning educational status, slightly more than one third $42.7 \%$ of respondents were no formal schooling. 
Table 1

Socio-demographic characteristics of pregnant women attending antenatal care at Jabitenhan district health centers, $2021 \quad(n=421)$

\begin{tabular}{|c|c|c|c|}
\hline Variables & Category & Frequency & Percent \\
\hline \multirow[t]{6}{*}{ Age } & $15-19$ & 47 & 11.1 \\
\hline & $20-24$ & 115 & 27.3 \\
\hline & $25-29$ & 140 & 33.3 \\
\hline & $30-34$ & 57 & 13.5 \\
\hline & $35-39$ & 42 & 10 \\
\hline & $>39$ & 20 & 4.8 \\
\hline \multirow[t]{2}{*}{ Religion } & Orthodox & 395 & 93.8 \\
\hline & Muslim & 26 & 6.2 \\
\hline \multirow[t]{2}{*}{ Marital status } & Married & 420 & 99.8 \\
\hline & Divorced & 1 & 0.2 \\
\hline \multirow[t]{5}{*}{ Occupation } & Housewife & 247 & 58.7 \\
\hline & Employed & 66 & 15.7 \\
\hline & Merchant & 74 & 17.6 \\
\hline & Student & 22 & 5.1 \\
\hline & Daily labor & 12 & 2.9 \\
\hline \multirow[t]{2}{*}{ Residence } & Urban & 181 & 43 \\
\hline & Rural & 240 & 57 \\
\hline \multirow[t]{2}{*}{ own income } & Yes & 140 & 33.3 \\
\hline & No & 281 & 66.7 \\
\hline \multirow[t]{4}{*}{ Educational status } & Illiterate & 180 & 42.7 \\
\hline & Primary school & 85 & 20.2 \\
\hline & Secondary school & 93 & 22.1 \\
\hline & College/university & 63 & 15 \\
\hline \multirow[t]{3}{*}{ Partner educational level } & Illiterate & 233 & 55.3 \\
\hline & Primary school & 36 & 8.6 \\
\hline & Secondary school & 50 & 11.9 \\
\hline
\end{tabular}




\begin{tabular}{|llll|}
\hline Variables & Category & Frequency & Percent \\
\hline & College/university & 102 & 24.2 \\
\hline
\end{tabular}

\subsection{Obstetric characteristics.}

Of 421 respondents $47.5 \%$ were primigravida and $48 \%$ were nulliparous. Of multigravida women, $52 \%$ had experienced obstetric complications in the previous pregnancy or labour or postpartum period and the majority $64.3 \%$ of respondents had no history of bad obstetric history (Table 2 ).

Table 2

Obstetric characteristics of pregnant women attending antenatal care at Jabitenhan district health centers, $2021(n=421)$

\begin{tabular}{|c|c|c|c|}
\hline Variable & Category & Frequency & Percen \\
\hline \multirow[t]{3}{*}{ Gravidity } & Primigravida & 200 & 47.5 \\
\hline & Multigravida & 169 & 40.1 \\
\hline & Grand multigravida & 52 & 12.4 \\
\hline \multirow[t]{4}{*}{ Parity } & Null & 202 & 48 \\
\hline & One & 77 & 18.3 \\
\hline & Two up to four & 112 & 26.6 \\
\hline & Five and above & 30 & 7.1 \\
\hline \multirow[t]{2}{*}{ Past obstetric complications } & Yes & 115 & 52 \\
\hline & No & 106 & 48 \\
\hline \multirow[t]{2}{*}{ Pregnancy danger signs } & Yes & 154 & 36.6 \\
\hline & No & 267 & 63.4 \\
\hline \multirow[t]{2}{*}{ Bad obstetric history } & Yes & 79 & 35.7 \\
\hline & No & 142 & 64.3 \\
\hline
\end{tabular}

\subsection{Knowledge of pregnancy danger signs.}

Vaginal bleeding (87.9\%) was the most common mentioned danger signs during pregnancy followed by loss of fetal movement $53.2 \%$, the onset of labour before the expected date of delivery $52.2 \%$ and persistent vomiting $48.4 \%$. The least mentioned danger signs during pregnancy were convulsion/ loss of consciousness $27.1 \%$ (Table 3 ) 
Table 3

Knowledge of pregnancy danger signs among pregnant women attending antenatal care at Jabitehnan district health centers, $2021(n=314)$

\begin{tabular}{|lll|}
\hline Variables & \multicolumn{2}{l|}{ Frequency (\%) } \\
\hline Awareness of pregnancy danger signs & Yes & No \\
\hline Vaginal bleeding & $276(87.9 \%)$ & $38(12.1 \%)$ \\
\hline Severe headache & $126(40.1 \%)$ & $188(59.9 \%)$ \\
\hline Persistent vomiting & $152(48.4 \%)$ & $162(51.6 \%)$ \\
\hline Swollen hand /face & $146(46.5 \%)$ & $168(53.5 \%)$ \\
\hline Severe abdominal pain & $100(31.8 \%)$ & $214(68.2 \%)$ \\
\hline Convulsion / Loss of consciousness & $85(27.1 \%)$ & $229(72.9 \%)$ \\
\hline Blurred vision/dizziness & $148(47.1 \%)$ & $166(52.9 \%)$ \\
\hline Loss of fetal movement & $167(53.2 \%)$ & $147(46.8 \%)$ \\
\hline Water break before labor & $141(44.9 \%)$ & $173(55.1 \%)$ \\
\hline The onset of labour before the expected date of delivery & $164(52.2 \%)$ & $150(47.8 \%)$ \\
\hline Persistent fever & $138(43.9 \%)$ & $176(56.1 \%)$ \\
\hline
\end{tabular}

\subsection{Pregnancy risk perception.}

In this study out of the total respondent's majority of women (51.7\%) did not perceive they were extremely susceptible to pregnancy-related complications but above half of the respondents $(60.1 \%)$ were perceived that they are susceptible to complications related to delivery and the postpartum period, and difficult pregnancy period. Each item means score pregnancy risk perception of pregnant women showed that they are not perceived for developing pregnancy-related complications. They are dichotomized to good perception (agree, strongly agree) and Poor perception (disagree, neutral, and strongly disagree)

Concerning the perceived severity of pregnancy-related complications, $57.9 \%$ perceived that pregnancy and delivery problems would last a long time while $55.9 \%$ of respondents perceived that Pregnancy complications would not threaten the relationship with my partner. The majority of the respondents $74.3 \%$ perceived that my baby will be born prematurely. $32.8 \%$ of respondents strongly agree that my baby would not survive the pressure that comes with labour and delivery (Table 4). 
Table 4

Pregnancy risk perception of pregnant women attending antenatal care at Jabitehnan district health centers, Ethiopia, 2021 $(\mathrm{n}=421)$

\begin{tabular}{|lllllll|}
\hline Variables & Frequency (\%) & & & & Mean(SD) \\
\hline $\begin{array}{l}\text { 1) Perceived } \\
\text { susceptibility }\end{array}$ & $\begin{array}{l}\text { Strongly } \\
\text { disagree }\end{array}$ & Disagree & Neutral & Agree & $\begin{array}{l}\text { Strongly } \\
\text { agree }\end{array}$ & \\
\hline $\begin{array}{l}\text { Getting } \\
\text { extremely } \\
\text { pregnancy- } \\
\text { related } \\
\text { complications }\end{array}$ & $105(24.9 \%)$ & $41(9.7 \%)$ & $69(16.5 \%)$ & $171(40.6 \%)$ & $35(8.3 \%)$ & $2.98(1.36)$ \\
\hline $\begin{array}{l}\text { Fears of having } \\
\text { difficult } \\
\text { pregnancy }\end{array}$ & $71(16.9 \%)$ & $58(13.7 \%)$ & $47(11.2 \%)$ & $193(45.8 \%)$ & $52(12.4 \%)$ & $3.23(1.31)$ \\
period. & & & & & & \\
$\begin{array}{l}\text { Good possibility } \\
\text { to get } \\
\text { complications } \\
\text { related to } \\
\text { delivery and the } \\
\text { postpartum } \\
\text { period }\end{array}$ & $62(14.7 \%)$ & $55(13.1 \%)$ & $51(12.1 \%)$ & $163(38.7 \%)$ & $90(21.4 \%$ & $3.39(1.35)$ \\
\hline $\begin{array}{l}\text { Getting } \\
\text { pregnancy- } \\
\text { related } \\
\text { complications }\end{array}$ & $84(19.9 \%)$ & $99(23.5 \%)$ & $56(13.3 \%)$ & $132(31.4 \%)$ & $50(11.9 \%)$ & $2.92(1.35)$ \\
are great & & & & & & \\
\hline $\begin{array}{l}\text { Get bad } \\
\text { pregnancy } \\
\text { outcome }\end{array}$ & $119(28.3 \%)$ & $78(18.5 \%)$ & $99(23.5 \%)$ & $100(23.8 \% 0$ & $25(5.9 \%)$ & $2.61(1.28)$ \\
\hline
\end{tabular}




\begin{tabular}{|c|c|c|c|c|c|c|}
\hline Variables & Frequency & & & & & Mean(SD) \\
\hline $\begin{array}{l}\text { 2) Perceived } \\
\text { severity }\end{array}$ & $\begin{array}{l}\text { Strongly } \\
\text { disagree }\end{array}$ & Disagree & Neutral & Agree & $\begin{array}{l}\text { Strongly } \\
\text { agree }\end{array}$ & \\
\hline $\begin{array}{l}\text { Pregnancy and } \\
\text { delivery } \\
\text { Problems would } \\
\text { last a long time. }\end{array}$ & $33(7.8 \%)$ & $44(10.5 \%)$ & $102(24.2 \%$ & 167(39.7\%) & 75(17.8\%) & $3.49(1.14)$ \\
\hline $\begin{array}{l}\text { Pregnancy } \\
\text { complications } \\
\text { would threaten } \\
\text { the relationship } \\
\text { with the partner }\end{array}$ & $101(24 \%)$ & $57(13.5 \%)$ & 73(17.3\%) & $103(24.5 \%)$ & $87(20.7 \%)$ & $3.04(1.47)$ \\
\hline $\begin{array}{l}\text { Pregnancy- } \\
\text { related } \\
\text { complications } \\
\text { can lead to } \\
\text { permanent } \\
\text { changes in life. }\end{array}$ & $46(10.9 \%)$ & $52(12.4 \%)$ & $64(15.2 \%)$ & $153(36.3 \%)$ & $106(25.2 \%)$ & $3.52(1.29)$ \\
\hline $\begin{array}{l}\text { Pregnancy } \\
\text { would not last to } \\
\text { term }\end{array}$ & $50(11.9)$ & $32(7.6 \%)$ & $56(13.3 \%)$ & $161(38.2 \%)$ & $122(29 \%)$ & $3.65(1.30)$ \\
\hline $\begin{array}{l}\text { The baby would } \\
\text { not survive the } \\
\text { pressure that } \\
\text { comes with } \\
\text { labour and } \\
\text { delivery. }\end{array}$ & $45(10.7 \%)$ & $47(11.2 \%)$ & $29(6.9 \%)$ & 162(38.4\%) & $138(32.8 \%)$ & $3.72(1.31)$ \\
\hline $\begin{array}{l}\text { If I got } \\
\text { pregnancy- } \\
\text { related } \\
\text { complications, I } \\
\text { fear I won't } \\
\text { survive them. }\end{array}$ & $88(20.9 \%)$ & $61(14.5 \%)$ & $40(9.5 \%)$ & $128(30.4 \%)$ & $104(24.7 \%)$ & $3.24(1.49)$ \\
\hline Premature birth & $36(8.6 \%)$ & $33(7.8 \%)$ & $39(9.3 \%)$ & $145(34.4 \%)$ & 168(39.9\%) & $3.89(1.25)$ \\
\hline
\end{tabular}

\subsection{Factors affecting pregnancy risk perception.}

In bivariable analysis, residence, own income, knowing a woman who died due to pregnancy-related complications, past obstetric complications, current pregnancy danger signs, the number of ANC visits, bad obstetric history, and awareness of pregnancy danger signs showed P-value less than 0.25 making them eligible for multivariable analysis.

In multivariable analysis awareness of pregnancy danger signs, bad obstetric history, past obstetric complications, and knowing a woman who died due to pregnancy-related complications were associated 
with pregnancy risk perception

Those who know at least one pregnancy danger sign were 5.2 times (AOR: $95 \% \mathrm{Cl}=5.22: 2.46,11.07$ ) more likely to have good pregnancy risk perception than their counterparts. Respondents who had bad obstetric history were 2.2 times (AOR: $95 \% \mathrm{Cl}=2.23: 1.13,4.41)$ more likely to have good pregnancy risk perception than their counterparts.

Respondents who had past obstetric complications were 3.44 times (AOR: $95 \% \mathrm{Cl}=3.44: 1.73,6.83$ ) more likely to have good pregnancy risk perception than their counterparts. Knowing women died due to pregnancy-related complications were 2.85 times (AOR: $95 \% \mathrm{Cl}=2.85: 1.45,5.60)$ more likely to have good pregnancy risk perception than their counterparts. (Table 5) 
Table 5

Factors affecting pregnancy risk perception of pregnant women attending antenatal care at Jabitenhan district health centers $2021(n=421)$

\begin{tabular}{|c|c|c|c|c|c|c|}
\hline \multirow[t]{2}{*}{ Variables } & & \multicolumn{2}{|c|}{$\begin{array}{l}\text { Pregnancy } \\
\text { risk } \\
\text { perception }\end{array}$} & \multirow[t]{2}{*}{$\operatorname{coR}(95 \% \mathrm{Cl})$} & \multirow[t]{2}{*}{$\mathrm{AOR}(95 \% \mathrm{Cl})$} & \multirow[t]{2}{*}{$\begin{array}{l}P \text { - } \\
\text { value }\end{array}$} \\
\hline & & Good & Poor & & & \\
\hline \multirow[t]{2}{*}{$\begin{array}{l}\text { Knowing at least one } \\
\text { pregnancy danger sign }\end{array}$} & Yes & 166 & 148 & $\begin{array}{l}2.21(1.39 \\
3.49)\end{array}$ & $5.22(2.46,11.07)$ & 0.000 \\
\hline & No & 36 & 71 & 1 & 1 & \\
\hline \multirow[t]{2}{*}{ Bad obstetric history } & Yes & 54 & 25 & $\begin{array}{l}2.49(1.40 \\
4.43)\end{array}$ & $2.23(1.13,4.41)$ & 0.022 \\
\hline & No & 66 & 76 & 1 & 1 & \\
\hline \multirow[t]{2}{*}{ Obstetric complication } & Yes & 78 & 37 & $\begin{array}{l}3.21(1.85 \\
5.58)\end{array}$ & $3.44(1.73,6.83)$ & 0.000 \\
\hline & No & 42 & 64 & 1 & 1 & \\
\hline \multirow[t]{2}{*}{$\begin{array}{l}\text { Having pregnancy } \\
\text { danger signs }\end{array}$} & Yes & 107 & 47 & $\begin{array}{l}\text { 4.12(2.69, } \\
6.30)\end{array}$ & $1.78(0.87,3.65)$ & 0.116 \\
\hline & No & 95 & 172 & 1 & 1 & \\
\hline \multirow{2}{*}{$\begin{array}{l}\text { Knowing women died } \\
\text { due to pregnancy-related } \\
\text { complications }\end{array}$} & Yes & 129 & 75 & $\begin{array}{l}3.39(2.27 \\
5.06)\end{array}$ & $2.85(1.45,5.60)$ & 0.002 \\
\hline & No & 73 & 144 & 1 & 1 & \\
\hline \multirow[t]{4}{*}{ Level of ANC visit } & Fourth & 49 & 43 & $\begin{array}{l}2.52(1.33 \\
4.79)\end{array}$ & $2.29(0.78,6.74)$ & 0.131 \\
\hline & Third & 68 & 59 & $\begin{array}{l}2.55(1.39 \\
4.67)\end{array}$ & $0.95(0.35,2.57)$ & 0.918 \\
\hline & Second & 62 & 66 & $\begin{array}{l}2.08(1.14 \\
3.80)\end{array}$ & $0.64(0.22,1.81)$ & 0.39 \\
\hline & First & 23 & 51 & 1 & 1 & \\
\hline \multirow[t]{2}{*}{ Residence } & Urban & 73 & 108 & $\begin{array}{l}0.58(0.39 \\
0.86)\end{array}$ & $\begin{array}{l}0.29(0.078 \\
1.11)\end{array}$ & 0.071 \\
\hline & Rural & 129 & 111 & 1 & 1 & \\
\hline \multirow[t]{2}{*}{ Own income } & Yes & 60 & 80 & $0.73(0.49,1.10)$ & $\begin{array}{l}3.52(0.89 \\
13.80)\end{array}$ & 0.093 \\
\hline & No & 142 & 139 & 1 & 1 & \\
\hline
\end{tabular}




\section{Discussion}

A major finding of this study was that above half of pregnant women had significantly poor risk perception. Out of the total study subjects, $48 \%(43.2 \%, 52.7 \%)$ had a good pregnancy risk perception. The independent variables that affect pregnancy risk perception were history of obstetric complications, knowing women who died due to pregnancy-related complications, bad obstetric history, and awareness of pregnancy danger sign.

In this study, $48 \%$ of pregnant women had a good pregnancy risk perception. Studies conducted at Health and Medical centers of Hamadan city in the west of Iran, 2 tertiary-care hospitals in Winnipeg, Manitoba, two major teaching hospitals of a city in Western Canada, and urban tertiary care hospital in western Canada showed that their mean score perception of pregnancy risk was below the midpoint of scales. It means that $100 \%$ of their study participants perceived that their susceptibility to pregnancy-related complications was mild. This difference might be due to that all the research conducted using a visual analog scale tool measurement which is only administered for literate people, data collection tool difference, sociocultural difference, sample size difference, and time gap of the study(26-29).

This study showed that $48.9 \%(43.9 \%, 53.7 \%)$ of study subjects perceived that they were susceptible to pregnancy-related complications. This finding was higher than studies conducted in Mandera County, Kenya $14.5 \%$. This difference might be due to socio-cultural differences of study participants, study population, and time gap of the study(25).

This research showed that $29.7 \%(25.7 \%, 34.4 \%)$ of pregnant women were perceived they are susceptible to bad pregnancy outcomes, $58.2 \%(53.7 \%, 62.9 \%)$ were perceived that they are susceptible to difficult pregnancy periods. This finding was consistent with the study conducted in Mandera County, Kenya $28.2 \%(25)$.

In this study, $74.3 \%(70.5 \%, 78.4 \%)$ of pregnant women perceived that their baby will be born prematurely. This result was consistent with studies conducted in Mandera County, Kenya 75\%. But studies conducted at Hamadan city Iran and Winnipeg, Manitoba showed that mean score perceptions were below the midpoint of scales that indicate mild risk perception. This difference might be due to the difference of measurement scale, socio-cultural difference, and time gap of the study $(25,26,28)$.

This study revealed that $45.1 \%(40.1 \%, 49.9 \%)$ of pregnant women were perceived that the occurrence of pregnancy complications would not threaten their relationship with their partners, which is lower than a study conducted in Mandera County, Kenya 51\%. This difference might be due to the socio-cultural difference of study participants and the time gap of the study. Besides, it may be because Ethiopian women's were honest with their husband to keep their promise during the marriage(25)

In this study, mean score perception pregnancy risk in pregnant women showed that they didn't perceive that they are at risk for dying due to pregnancy-related complications. Studies conducted in Winnipeg, Manitoba, Western Canada, and the west of Iran had mild risk perception. This difference may be due to 
difference in measurement scale, data collection tool, socio-cultural difference, and educational status of respondents (26-29)

Approximately seventy percent of women perceived that their babies will be dying during labour and delivery. This result was inconsistent with studies conducted in western Canada and Hamadan city in the west of Iran. This difference may be due to difference in measurement scale, socio-cultural difference, and educational status of respondents $(26,27)$

The study also revealed that women having a history of obstetric complications were more likely to have positive pregnancy risk perception. This may be because these women had information about pregnancyrelated complications from their experience of obstetric complications and understand their risk of susceptibility.

Pregnant women who had awareness of pregnancy danger signs were more likely to have positive pregnancy risk perception than their counterparts. This may be due to knowledge about pregnancy danger sign clears rumor about pregnancy-related complication and increase their awareness about pregnancy-related complications.

According to this study, pregnant women with bad obstetric history were more likely to have positive pregnancy risk perception. This may be due to pregnant women familiarized with the bad obstetric outcome and learned their susceptibility towards pregnancy-related complications.

In this research one of the factors that affecting positively, pregnancy risk perception was knowing a woman who died due to pregnancy-related complications. This may be because these women learned the probability of developing pregnancy-related complications as well as the consequences of pregnancyrelated complications from women's died due to pregnancy-related complications.

Generally, pregnant women with a bad obstetric history, past obstetric complication and knew a woman who died due to pregnancy-related complications was associated with pregnancy risk perception. This result was similar to the concept of availability of the Heuristic approach which means that an individual makes a judgment about likely hood of an event based on past experience or information from others(3). In this study past experience and information from others are pregnant women with bad obstetric history and past obstetric complications, and knew a woman who died due to pregnancy-related complications respectively.

In this study age of pregnant women is not significantly associated with pregnancy risk perception. But women aged $<18$ years had a statistically significantly associated to pregnancy risk perception than women aged 18 to 35 in studies conducted at Health and Medical centers of Hamadan city in the west of Iran(26). This difference might be due sample size difference (421 pregnant women versus 240 pregnant women), age category difference (15-43 years versus < 35 years), study participant difference (both nulliparous and multiparous versus only nulliparous) and measurement scale differences (Likert scale versus visual analog scale) and the difference in data collection tools. 


\section{Conclusion}

These studies showed that pregnant women perceive that they were risky in developing pregnancy-related complications and their consequences were low. Only forty-eight percent of pregnant women had good pregnancy risk perception. This is likely to have implications for medical care and pregnancy outcomes.

History of obstetric complication and bad obstetric history was associated with a higher degree of actual risk perception in pregnancy whilst women who knew the death of pregnant women due to pregnancy complication and knowing at least one pregnancy danger signs were more likely to be concerned about risk.

\section{Declarations}

\section{Consent for publication:}

Not applicable

\section{Availability of data and materials:}

The original data for this study are available from the corresponding author on reasonable request.

\section{Competing interest:}

The authors declare that there are no conflicts of interest regarding the publication of this paper.

\section{Funding:}

Hailu Alemu College funded this study.

\section{Author's contribution:}

DA and wrote study design, data entry, data analysis and result.

AM data analysis, result, prepare manuscript, read and approve final manuscript.

WK co-advisor, LB main-advisor and DM data collection and data entry.

\section{Acknowledgments}


We would like to thank Hailu Alemu College for financial support to this study and Debre Markos University for granting permission to this study.

\section{References}

1. Sjöberg L. The methodology of risk perception research. Quality and Quantity. 2000;34(4):407-18.

2. Darker C. Risk Perception. In: Gellman MD, Turner JR, editors. Encyclopedia of Behavioral Medicine. New York, NY: Springer New York; 2013. p. 1689-91.

3. Tversky A, Kahneman D. Judgment under uncertainty: Heuristics and biases. science. 1974;185(4157):1124-31.

4. Jackson, Jonathan, Allum, Nick and Gaskell, George (2006) Bridging levels of analysis in risk perception research: the case of the fear of crime. Forum Qualitative Sozialforschung / Forum: Qualitative Social Research, 7 (1). Art. 20. ISSN 1438-5627

5. Atkinson SJ, Farias MF. Perceptions of risk during pregnancy amongst urban women in northeast Brazil. Social Science \& Medicine. 1995;41(11):1577-86.

6. Kowalewski M, Jahn A, Kimatta SS. Why do at-risk mothers fail to reach referral level? Barriers beyond distance and cost. African journal of reproductive health. 2000;4(1):100-9.

7. Suplee PD, Dawley K, Bloch JR. Tailoring peripartum nursing care for women of advanced maternal age. Journal of Obstetric, Gynecologic \& Neonatal Nursing. 2007;36(6):616-23.

8. Fraser M, Cooper MA. Myles text book for midwives. Midwifery. 2003;33(3):752.

9. Agus Y, Horiuchi S, Porter SE. Rural Indonesia women's traditional beliefs about antenatal care. BMC research notes. 2012;5(1):1-8.

10. Gabrysch S, Campbell OM. Still too far to walk: literature review of the determinants of delivery service use. BMC pregnancy and childbirth. 2009;9(1):1-18.

11. Baral Y, Lyons K, Skinner J, Van Teijlingen E. Determinants of skilled birth attendants for delivery in Nepal. Kathmandu University Medical Journal. 2010;8(3):325-32.

12. Nambala BS, Ngoma C. Knowledge and perception of women towards danger signs in pregnancy in Choma rural district, Zambia. Med J Zambia. 2013;40(2):43-7.

13. Wassihun B, Negese B, Bedada H, Bekele S, Bante A, Yeheyis T, et al. Knowledge of obstetric danger signs and associated factors: a study among mothers in Shashamane town, Oromia region, Ethiopia. Reprod Health. 2020 Dec;17(1):1-8.

14. Nurgi S, Tachbele E, Dibekulu W, Wondim MA. Knowledge, attitude and practice of obstetric danger signs during pregnancy in Debre Berhan, Ethiopia. Health Science Journal. 2017;11(6):1-7.

15. Hiluf $M$, Fantahun $M$. Birth preparedness and complication readiness among women in Adigrat town, north Ethiopia. Ethiopian Journal of Health Development. 2008;22(1):14-20.

16. Mekonnen W, Gebremariam A. Causes of maternal death in Ethiopia between 1990 and 2016: systematic review with meta-analysis. Ethiopian Journal of Health Development. 2018;32(4). 
17. Say L, Chou D, Gemmill A, Tunçalp Ö, Moller A-B, Daniels J, et al. Global causes of maternal death: a WHO systematic analysis. Lancet Glob Health. 2014 Jun;2(6): e323-33.

18. World Health Organization. International statistical classification of diseases and related health problems [Internet]. World Health Organization; 2015 [cited 2021 Aug 25]. Available from: https://apps.who.int/iris/handle/10665/246208

19. World Health Organization. Trends in maternal mortality 2000 to 2017: estimates by WHO, UNICEF, UNFPA, World Bank Group and the United Nations Population Division: executive summary [Internet]. World Health Organization; 2019 [cited 2021 Aug 25]. Report No.: WHO/RHR/19.23. Available from: https://apps.who.int/iris/handle/10665/327596.

20. Conde-Agudelo A, Belizán JM, Lammers C. Maternal-perinatal morbidity and mortality associated with adolescent pregnancy in Latin America: Cross-sectional study. American journal of obstetrics and gynecology. 2005;192(2):342-9.

21. Knight HE, Self A, Kennedy SH. Why are women dying when they reach hospital on time? A systematic review of the 'third delay'. PloS one. 2013;8(5): e63846.

22. Rajbanshi S, Norhayati MN, Nik Hazlina NH. Risk perceptions among high-risk pregnant women in Nepal: a qualitative study. BMC Pregnancy Childbirth. 2021 Dec;21(1):1-8.

23. Central Statistical Agency (Ethiopia) | GHDx [Internet]. [cited 2021 Aug 25]. Available from: http://ghdx.healthdata.org/organizations/central-statistical-agency-ethiopia

24. Meseret M, Shibabaw M, Tsegaye G. Determinants of tuberculosis among adults in Jabi Tehnan district, West Gojjam zone, Northwest Ethiopia: a case control study. International Journal of Public Health \& Safety. 2017;2(3):1000128.

25. Uptake of Antenatal Care Services among Women of Reproductive Age in Mandera County, Kenya I African Journal of Health Sciences [Internet]. [cited 2021 Aug 25]. Available from: https://www.ajol.info/index.php/ajhs/article/view/197770

26. Taghizadeh Z, Cheraghi MA, Kazemnejad A, Pooralajal J, Aghababaei S. Difference in perception of pregnancy risk in two maternal age groups. Journal of clinical and diagnostic research: JCDR. 2017;11(5): QC09.

27. Gupton A, Heaman M, Cheung LWK. Complicated and uncomplicated pregnancies: women's perception of risk. Journal of Obstetric, Gynecologic, \& Neonatal Nursing. 2001;30(2):192-201.

28. Bayrampour $\mathrm{H}$, Heaman M, Duncan KA, Tough S. Comparison of perception of pregnancy risk of nulliparous women of advanced maternal age and younger age. Journal of Midwifery \& Women's Health. 2012;57(5):445-53.

29. Heaman M, Beaton J, Gupton A, Sloan J. A comparison of childbirth expectations in high-risk and low-risk pregnant women. Clinical Nursing Research. 1992;1(3):252-65.

\section{Figures}




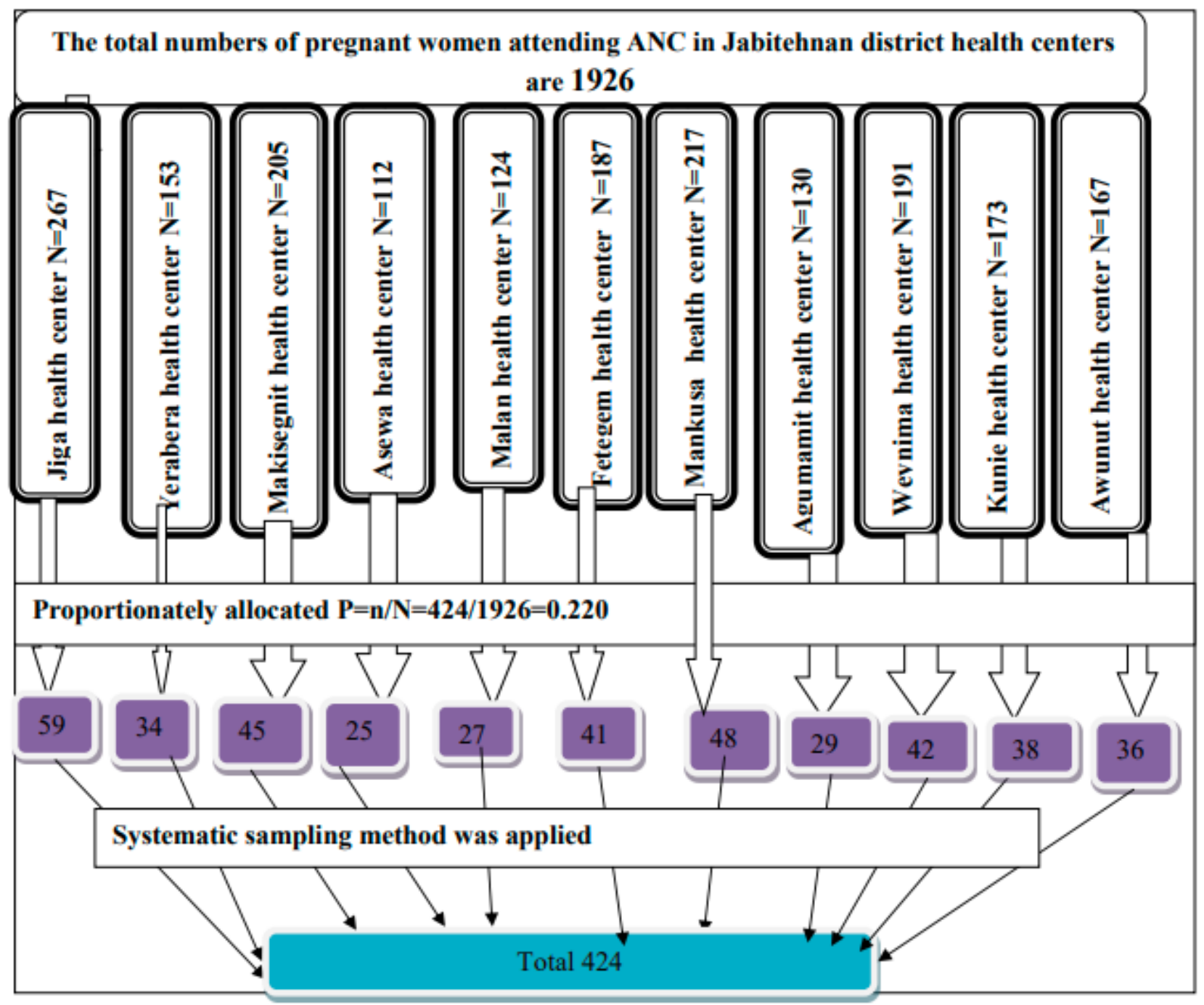

Figure 1 sampling procedure to determine pregnancy risk perception and associated factors among pregnant women attending antenatal care at health centers in Jabitehnan district, Amhara, northwest Ethiopia, 2021

Figure 1

Please See image above for figure legend. 